Short communication

\title{
Goals for oral health in Tunisia 2020
}

F. Maatouk, ${ }^{7}$ B. Jmour, ${ }^{1}$ H. Ghedira, ${ }^{7}$ A. Baaziz, ${ }^{1}$ L. Ben Hamouda ${ }^{2}$ and A. Abid ${ }^{1}$

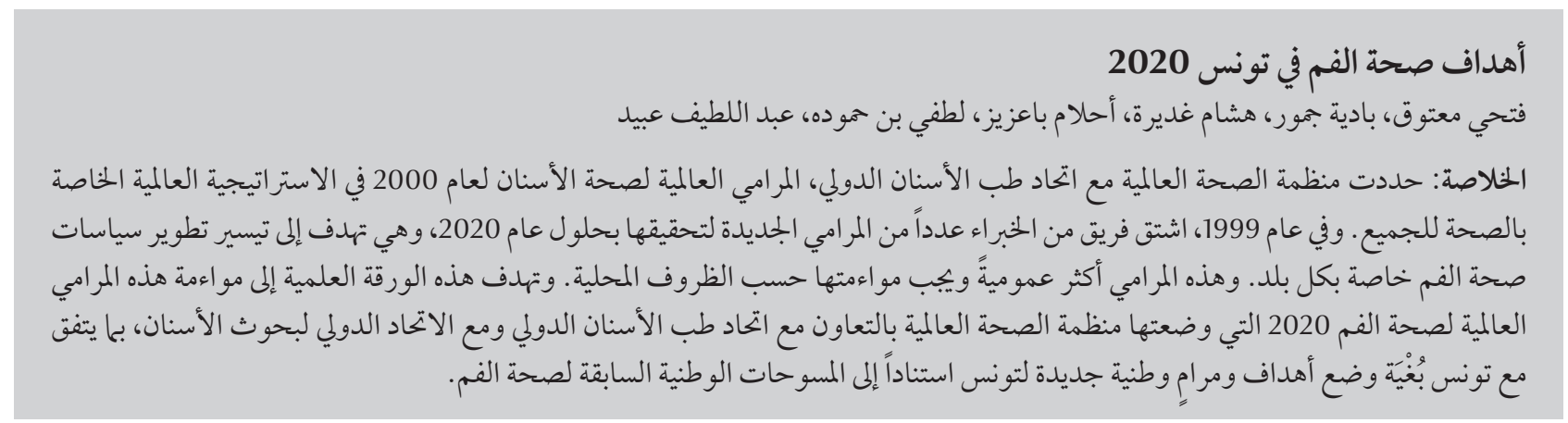

ABSTRACT In 1981, the World Health Organization (WHO) together with the Fédération Dentaire Internationale (FDI) set global dental health goals for the year 2000 within the global strategy of health for all. In 1999, a team of experts drew up new goals to be achieved by 2020, which aimed to facilitate specific oral health policy development for each country. These goals are more general and have to be adapted to local circumstances. This paper aimed to adapt the WHO/FDI/IADR's Global goals for oral health 2020 to Tunisia and draw up new national goals and targets for Tunisia based on previous national oral health surveys.

\section{Objectifs pour la santé bucco-dentaire en Tunisie en 2020}

RÉSUMÉ En 1981, I'Organisation mondiale de la Santé ainsi que la Fédération Dentaire Internationale ont défini des objectifs mondiaux en santé bucco-dentaire pour l'année 2000 dans le cadre de la stratégie mondiale de la Santé pour tous. En 1999, une équipe d'experts a établi de nouveaux objectifs à réaliser d'ici 2020, visant à promouvoir l'élaboration de politiques de santé bucco-dentaire propres à chaque pays. Ces objectifs sont plus généraux et doivent être adaptés au contexte local. Le présent article visait à adapter à la Tunisie les objectifs mondiaux en matière de santé bucco-dentaire pour 2020 mis au point par l'Organisation mondiale de la Santé, la Fédération Dentaire Internationale et l'Association internationale de Recherche dentaire et à établir de nouveaux objectifs et cibles pour le pays à partir des enquêtes nationales de santé bucco-dentaires existantes. 


\section{Introduction}

Among the oral diseases, dental caries and periodontal affections are the most widespread in the world, especially in school-age children from developing countries. The prevalence of these diseases continues to increase in these countries while they decrease in developed countries [1]. Thus, all developing countries need to give the highest priority to oral health promotion according to the principles of the Ottawa Charter [2].

In this context, the World Health Organization (WHO) adopted a global strategy of Health for All by the year 2000 and set jointly with the Fédération Dentaire Internationale (FDI) the first global health goals in $1981[3,4]$. These was very useful as they stimulated awareness of the importance of oral health and acted as a catalyst for securing resources in this field [5].

In 1999, experts from WHO, FDI and the International Association of Dental Research (IADR) working closely together noted that the "first global goals by the year 2000" were not only quantitative in character but also not applicable equally to all countries and all populations. They remain only a remote aspiration for many countries, especially the developing ones [6].

Therefore, experts drew up new goals, the Global Goals for Oral Health 2020 based on oral diseases classification and established criteria for their diagnosis [6]. These new goals are more general and no absolute values are given as these must be established on the basis of the local circumstances, such as disease prevalence and the socioenvironmental conditions.

Combined with a list of the most important health problems and the available resources in the community, these goals will help experts to identify the most appropriate interventions needed for oral health promotion.
This paper aimed to adapt the new Global Goals for Oral Health to a Tunisian setting and to draw up national goals for oral health in Tunisia by the year 2020. It will also provide the first step in the process of updating a Tunisian National Oral Health Strategy by guiding health planners to evaluate the current situation of oral health.

\section{Specific background}

In Tunisia, where the young under the age of 20 years constitute $47 \%$ of the total population, great attention has been given to their health by the authorities [7].

For this purpose, the National Oral Health Programme was founded in 1991 by the Public Health Ministry. It aimed to promote oral health in schoolchildren by providing the needed tools and support [8]. The overall goal of this programme was the reduction of morbidity due to oral diseases with consequent improvement in quality of life. The specific goals were notably:

- To improve and reinforce the detection and early diagnosis of oral diseases;

- To promote the necessary oral health care for affected children;

- To promote oral health education in school and its integration in school courses;

- To ensure life-long learning for oral health workers;

- To reinforce systems and measures for oral health evaluation and followup;

- To promote partnership and scientific research in oral health prevention field and in evidence-based dental care.

The programme focused on schoolchildren as they constitute an important target group for oral prevention; indeed, they are more exposed to oral conditions than others. Schoolchildren are also grouped and easily accessible to provide preventive measures; furthermore they are more receptive to educational messages than adults [8].

Four national oral health surveys in schoolchildren were performed in Tunisia by Abid [9] in 1981, the Tunisian Paediatric Dentistry Association [10] in 1988 and by the Public Health Ministry in cooperation with WHO in 1994 (TUN/ORH/001) [11] and in 2003 (TUN/HPR/OOO/RB/02) [7]. The first two surveys had many data missing and therefore could not be used to establish baseline information.

The third survey was carried out to establish the oral health baseline prior to introducing the National Oral Health Programme [11]. The fourth survey aimed to:

- Update the available data on the oral health status of schoolchildren 6, 12 and 15 years old and to analyse the trends in oral health and disease since 1994;

- Assess the oral health situation of the studied population and to estimate its needs in care and in oral health education;

- Assess the steps taken in the National Oral Health Programme to promote the oral health and to improve the main health parameters;

- Adjust and revise the goals of the oral health strategies according to the WHO recommendations after the third survey;

- Estimate for the first time in Tunisia, the oral health status and the knowledge, practice and attitudes towards oral health of adults aged 35 to 44 years [12].

The findings confirmed that dental caries and periodontal diseases are the most frequent oral conditions among schoolchildren as revealed by the WHO report in developing countries [13]. Indeed a high prevalence of dental caries was noted both in primary dentition at 6 years $(56.3 \%)$ and in permanent dentition at 12 years (49.1\%). The decayed, missing and filled teeth (DMFT) index 
at 12 years was about 1.4 with a very high $\mathrm{D}$ component (1.33) and a low F component (0.03), which shows a great insufficiency in treatment. Poor oral hygiene was common among 15-year-old schoolchildren and periodontal troubles (especially calculus) constituted a serious problem in 38\% of them. In addition, malocclusion was more frequent in schoolchildren (40.7\%) in Tunisia than in other countries of the East Mediterranean Region (EMR) [7] and dental fluorosis was endemic in some regions of the country $(40.7 \%)$ as in some other African countries $[14,15]$.

In adults ( 35 to 44 years old), more than $73 \%$ suffered from dental caries and periodontal problems; the mean DMFT score was about 5.6 and consisted mainly of $\mathrm{D}$ component (3.0) with a low therapeutic index (0.45).

In 2008, the Tunisian Society of Oral Health for Elderly People conducted a national survey involving 816 adults aged 65 years and over [16]. The aim of this epidemiological study was to assess, for the first time in Tunisia, the oral health indicators of elderly people and to estimate their dental treatment needs, especially the prosthetic needs. The results showed that more than half of the subjects had dental caries while $80 \%$ had periodontal problems and 32\% were totally edentulous.

\section{Goals, objectives and targets for oral health in Tunisia 2020}

As done in other countries $[17,18]$, the following goals, objectives and targets are proposed based on the findings of the latest epidemiological studies taking into consideration the Tunisian political, socioeconomic and legislative context.

\section{Goals}

- To promote oral health and to reduce the impact of oral and craniofacial diseases on health and psychosocial development, especially amongst schoolchildren and at-risk groups.

- To minimize the oral and craniofacial impact of systemic diseases on individuals and groups by early detection, prevention and effective care.

\section{Objectives}

- To reduce mortality due to oral and craniofacial diseases.

- To reduce morbidity due to oral and craniofacial diseases and to improve quality of life.

- To promote necessary policies and oral health programmes derived from systematic reviews of the best practices (i.e. evidence-based policies).

- To develop accessible and cost-effective oral health systems for the prevention and control of oral and craniofacial diseases.

- To integrate oral health promotion and care in other sectors that influence health (account being taken of common risk factors).

- To empower people to control determinants of health.

- To develop systems and measures for oral health evaluation (both processes and outcomes).

- To promote social responsibility and ethical practices in the dental profession.

- To reduce the inequalities in oral health indicators across regions.

- To increase the number of dentists trained in epidemiological follow-up of oral diseases.

\section{Targets}

According to the framework proposed by WHO, FDI and IADR [6] and the Tunisian situation, the targets to be achieved by the year 2020 are outlined below.

\section{Dental caries}

- Increase the proportion of cariesfree in primary dentition to $60 \%$ for 6-year-olds. Baseline:

- proportion of 6-year-olds with naturally healthy dentition $43.3 \%$ in 1994 [10] and $43.7 \%$ in 2003 [7].

- Reduce DMFT index in 12-year-olds to less than 1.0 with special attention to high risk groups. Reduce by 50\% the proportion of 12-year-olds with high levels of caries (DMFT index > 2). Baseline:

- average DMFT in 12-year-olds was 1.3 in 1994 [10] and 1.4 in $2003[7]$

- proportion of 12-year-olds with high levels of caries in 2003 was about 30\%

- Reduce DMFT index in 15-yearolds to 1.0 with special attention to high-risk groups. Reduce by 50\% the proportion of 15-year-olds with high levels of caries (DMFT index > 2). Baseline:

- average DMFT in 15-year-olds in $1994^{10}$ and 2003 [7] was 2.0;

- proportion of 15-year-olds with high levels of caries in 2003 was $34.8 \%$.

- Reduce the average number of missing teeth due to dental caries to 1.2 in adults aged 35-44 years. Baseline:

- average number of missing teeth due to dental caries in adults aged 35-44 years in 2003 was $2.2[7]$.

- Reduce the average number of missing teeth due to dental caries to 14 in adults $\geq 65$ years. Baseline:

- average number of missing teeth due to dental caries in adults $\geq 65$ years in 2008 was 15.8 [16].

\section{Periodontal diseases}

- Reduce the prevalence of active periodontal diseases (with or without loss of attachment and with special reference to calculus) to $30 \%$ in 
15-year-old schoolchildren, to $65 \%$ in adults aged $35-44$ years and to $75 \%$ in adults aged $\geq 65$ years. Baseline:

- prevalence of active periodontal diseases in 15-year-old schoolchildren in 1994 was about 70\% (60\% with calculus) [10] and about 38\% (17\% with calculus) in 2003 [7]

- prevalence of active periodontal diseases in adults aged 35-44 years in 2003 was about $72 \%$ (37\% with calculus) [7]

- prevalence of active periodontal diseases in adults aged $\geq 65$ years in 2008 was about $79 \%$ (63\% with calculus) [16].

\section{Tooth loss and edentulousness}

- Reduce the prevalence of total edentulousness to less than $20 \%$ in adults aged $\geq 65$ years. Baseline:

- prevalence of total edentulousness in adults aged $\geq 65$ years in 2008 was $32 \%$ [16].

- Increase the proportion of people with all their natural teeth $(\geq 28)$ to $80 \%$ in adults aged $35-44$ years and to $25 \%$ in adults aged $\geq 65$ years. Baseline:

- percentage of people with all their natural teeth $(\geq 28)$ in adults aged $35-44$ years was about $74 \%$ in 2003 [7]

- percentage of people with all their natural teeth $(\geq 28)$ in adults aged $\geq 65$ years was about $21 \%$ in 2008 [16].

\section{Malocclusion}

- Reduce malocclusion (mild, moderate and severe) prevalence in children aged 6, 12 and 15 years to $35 \%$ and to $40 \%$ in adults aged $35-44$ years. Baseline:

- percentage of children aged 6,12 and 15 years with all types of malocclusion was about 37\% in 1994 [10] and 41\% in 2003

- prevalence of malocclusion was about $44 \%$ in adults aged $35-44$ years in 2003 [7].

\section{Dental fluorosis (developmental anomalies of teeth)}

- Reduce dental fluorosis prevalence in children aged 12 and 15 years to $25 \%$ and to $40 \%$ in adults aged $35-44$ years. Baseline:

- percentage of subjects with dental fluorosis defects in 12- and 15 -year-olds was about $26 \%$ in 1994 [10] and 35\% in 2003; the percentage was about $50 \%$ in adults aged 35-44 years in 2003 [7].

\section{Tobacco consumption}

- Reduce tobacco smoking (risk factors for many oral conditions notably oral cavity cancer) to $2 \%, 20 \%$ and $10 \%$ respectively in 15 -year-olds, in 35-44-years-olds and adults $\geq 65$ years. Baseline:

- percentage of smokers in 15-yearolds was about $2.5 \%$ in 1994 [10] and about $4.1 \%$ in 2003 [7]

- percentage of smokers in adults aged $35-44$ years was about $25 \%$ in 2003 [7]

- percentage of smokers in adults aged $\geq 65$ years was about $17 \%$ in 2008 [16].

\section{Oral health care information}

- Increase the proportion of the population covered by satisfactory oral health information to $80 \%$ in schoolchildren (notably by reviewing the school curriculum) and to $85 \%$ in adults aged 35-44 years. Baseline:

- percentage of schoolchildren (6, 12 and 15 years) covered by satisfactory oral health information in 2003 was about $63 \%$ [7]

- percentage of adults aged 35-44 years covered by satisfactory oral health information in 2003 was about $72 \%$ [7].

\section{Health care services access}

- Increase to $70 \%$ the proportion of the population with access to adequate oral health care in schoolchildren. Increase the proportion to $50 \%$ in adults aged $35-44$ years and $20 \%$ in adults aged $\geq 65$ years. Baseline:

- percentage of subjects with access to adequate oral health in 2003 was about $63 \%$ for schoolchildren, 43\% for adults aged 35-44 years [7] and $16 \%$ for adults aged $\geq 65$ years in 2008 [16].

\section{Update and complete oral health} data base

The prevalence of major oral and maxillofacial diseases, associated with other factors such as the level of care and need for treatment, constitute the basis for the formulation of the current oral health goals. Thus epidemiological studies must be carried out to obtain detailed knowledge about the common oral conditions and other important conditions, such as trauma, oral cavity cancer, oral manifestation of HIV infection and tobacco smoking. Furthermore, the number of health care providers who are competent to diagnose and provide emergency care for these conditions must be increased.

Table 1 summarises selected indicators related to the proposed objectives, their previous values as well as the targets set for 2020 .

\section{Discussion}

We present here suggested oral health goals for Tunisia for 2020. The paper shows how an international template can be adapted to a national setting and gives some of the details of the work that should be done in countries that have a national oral health plan in the process of being updated and adapted.

The goals and targets were drawn up based on the results of the latest epidemiological studies on oral health in Tunisia.

Although the methodology for determining these goals may be open to debate and some of the suggested targets may seem too modest in terms of desired improvement, without goals and 


\begin{tabular}{|c|c|c|c|c|c|}
\hline \multirow[t]{2}{*}{ Indicator } & \multirow[t]{2}{*}{ Age (years) } & \multicolumn{3}{|c|}{ Evolution of indicators } & \multirow{2}{*}{$\begin{array}{l}\text { Target } \\
2020\end{array}$} \\
\hline & & 1994 & 2003 & 2008 & \\
\hline $\mathrm{dft}=0(\%)$ & 6 & 43.3 & 43.7 & - & 60 \\
\hline \multirow[t]{2}{*}{ DMFT } & 12 & 1.3 & 1.4 & - & $<1.0$ \\
\hline & 15 & 2.0 & 2.0 & - & 1.0 \\
\hline \multirow[t]{2}{*}{ High level of caries (DMFT > 2) (\%) } & 12 & 28 & 29.6 & - & 15 \\
\hline & 15 & 35 & 34.8 & - & 17.5 \\
\hline \multirow[t]{2}{*}{ Missing teeth for caries (mean) } & $35-44$ & - & 2.2 & - & 1.2 \\
\hline & $\geq 65$ & - & - & 15.8 & 14.0 \\
\hline \multirow[t]{3}{*}{ Active periodontal infection (\%) } & 15 & 70 & 38 & - & 30 \\
\hline & $35-44$ & - & 72.2 & - & 65 \\
\hline & $\geq 65$ & - & - & 79 & 75 \\
\hline Edentulous (\%) & $\geq 65$ & - & - & 32 & $<20$ \\
\hline \multirow[t]{2}{*}{ People with at least 28 teeth (\%) } & $35-44$ & - & 74 & - & 80 \\
\hline & $\geq 65$ & - & - & 20.7 & 25 \\
\hline \multirow[t]{2}{*}{ Malocclusion (\%) } & 6,12 and 15 & 37 & 40.7 & - & 35 \\
\hline & $35-44$ & - & 43.7 & - & 40 \\
\hline \multirow[t]{2}{*}{ Fluorosis (\%) } & 12 and 15 & 26 & 35.2 & - & 25 \\
\hline & $35-44$ & - & 50 & - & 40 \\
\hline \multirow[t]{3}{*}{ Tobacco smoking } & 15 & 2.5 & 4.1 & - & 2 \\
\hline & $35-44$ & - & 25.1 & - & 20 \\
\hline & $\geq 65$ & - & - & 16.6 & 10 \\
\hline \multirow[t]{2}{*}{ People having oral health information (\%) } & 6,12 and 15 & - & 63 & - & 80 \\
\hline & $35-44$ & - & 72 & - & 85 \\
\hline \multirow[t]{3}{*}{ Access to oral care (\%) } & 6,12 and 15 & - & 63 & - & 70 \\
\hline & $35-44$ & - & 43 & - & 50 \\
\hline & $\geq 65$ & - & - & 16 & 20 \\
\hline
\end{tabular}

$-=$ not available $; f f=$ decayed, filled teeth; DMFT = decayed, missing, filled teeth .

focussed targets little can be achieved, particularly for prevention. Indeed, in spite of the efforts made by the Ministry of Public Health, there were no notable improvements between the findings of the survey in 1994 and those of the 2003 survey, except concerning periodontal conditions. Insufficient efforts for the prevention and control of oral diseases can explain this fact in association with a lack of sufficient awareness of the importance of oral health in children and adults. In addition, the fact that more than $76 \%$ of Tunisian dentists work in the private sector, leaving an inadequate number employed in the National Oral Health Programme, is another factor hindering improvement in oral health.

After careful consideration and analysis of the Global goals for oral health
2020, some important points emerge and should be considered.

- The WHO/FDI/IADR's goals include both disease-related aspects and the promotion of health and prophylaxis [17]. They are more general than the first goals in 1981 and as such should encourage local action by focusing on the global level. However, they run the risk of seeming too general and vague. In addition, they encompass several medical specialties (e.g. dentistry, maxillofacial surgery, otolaryngology, oncology), which do not necessarily have the same priorities or the same care approach.

- These goals must support much more prevention and primary health care.
- The goals do not seem equally applicable to all countries so specific goals should be formulated for developing countries because appropriate differentiation seems to be important.

- Attention should also be given to medically compromised subjects and at-risk groups, such as children with congenital heart disease or epilepsy.

In conclusion, we need to work together in order to achieve these goal and improve and safeguard the oral health in Tunisia.

\section{Acknowledgements}

Special thanks are due to $\mathrm{Mr}$ S. Boukottaya, English teacher, for his most valuable help. 


\section{References}

1. Pakhomov GN. Future trends in oral health and disease. International Dental Journal, 1999, 49:27-32.

2. Ottawa Charter for Health Promotion. First International Conference on Health Promotion, Ottawa, 21 November 1986. Geneva, World Health Organization, 1986 (WHO/HPR/ HEP/95.1) (http://www.who.int/hpr/NPH/docs/ottawa_ charter_hp.pdf, accessed 4 September 2011).

3. Formulating strategies for health for all by the year 2000. Geneva, World Health Organization, 1979.

4. Global goals for oral health in the year 2000. Fédération Dentaire Internationale. International Dental Journal, 1982, 32:74-77.

5. Beiruti N. Views on oral health care strategies. Eastern Mediterranean Health Journal, 2005, 11:209-216.

6. Hobdell M et al. Global goals for oral health 2020. International Dental Journal, 2003, 53:285-288.

7. Abid A. Oral health in Tunisia. International Dental Journal, 2004, 54:389-394.

8. The National Oral Health Programme. Tunis, School Health Department, Ministry of Public Health, 2009.

9. Abid A. Enquête nationale sur la santé bucco-dentaire [National oral health survey]. L'Information Dentaire, 1984, 66:2219-2228.

10. Smaoui N. Évaluation de la santé bucco-dentaire des enfants tunisiens à travers trois enquêtes nationales [Oral health evaluation in Tunisian children through three national surveys]. [Thesis]. Monastir, Tunisia, Dentistry School of Monastir, 1997.

11. Maatouk F et al. School oral health survey in Kairouan, Tunisia. Eastern Mediterranean Health Journal, 1998, 4:137-141.

12. Second national survey on oral health in schoolchildren and adults in Tunisia. Tunis, School Health Department. Ministry of Public Health, 2007.

13. Petersen PE. The world oral health report 2003: continuous improvement of oral health in the 27st century - the approach of the WHO Global Oral Health Programme. Geneva, World Health Organization, 2003.

14. Maatouk F et al. Dental fluorosis in Kairouan, Tunisia. Dental News, 1998, 1(1):17-19.

15. Akpata ES. Oral health in Nigeria. International Dental Journal, 2004, 54 Suppl 1;361-366.

16. Enquête nationale sur la santé bucco-dentaire des personnes âgées en Tunisie [National survey on oral health in elderly persons in Tunisia]. Monastir, Tunisian Society of Gerodontology 2008.

17. Ziller $\mathrm{S}$ et al. Goals for oral health in Germany 2020. International Dental Journal, 2006, 56:29-32.

18. Bravo M et al. Basic oral health goals for Spain 2015/2020. International Dental Journal, 2009, 59:78-82, quiz 62. 